\title{
Calculation of IOL power after refractive surgery
}

\author{
Ioannis Mallias, Panagiota Mylova, Anastasia Tassiopoulou
}

Laser Plus Eye, Nea Smyrni, Athens, Greece

\begin{abstract}
The purpose of this article is to identify and describe the methods used nowadays to calculate intraocular lens (IOL) power in post refractive surgery patients. All the reasons why the standard way of calculating IOL power do not work in post refractive surgery patients are analysed. Moreover, other formulas that can calculate the IOL power are described. The importance for the surgeon to understand the advantages and limitations of each method is stressed. The necessity of new, even more accurate methods to exist is also pointed out.
\end{abstract}

KEY WORDS: intraocular lens calculation, IOL power, post refractive surgery cataract surgery, IOL calculation formulas

Ophthalmol J 2017; Vol. 2, No. 2, 44-48

\section{INTRODUCTION}

Patients who have undergone laser vision correction (LASIK or photorefractive keratectomy - PRK) or radial keratotomy have had modifications to their corneal curvatures. Calculating intraocular lens (IOL) power in such patients has been a subject of a significant amount of research over the years [1-4]. The correct IOL calculation is very important for patient satisfaction. Patients that have undergone refractive surgery have less tolerance to correcting any possible remaining refractive error with spectacles, and their expectations of cataract surgery are unusually high.

Since myopic refractive surgery has been the most popular procedure, the majority of research has been focused there. However, there are significant differences in the IOL calculation of other refractive procedures, such as hyperopic LASIK or radial keratotomy. IOL calculation is based upon some parameters, such as corneal power and axial length. Modern two-variable, third-generation formulas, such as SRK/T, Hoffer Q, and Holladay 1, use these variables to calculate the IOL power [5].

The most obvious reason for the inaccuracy of IOL power calculation after refractive surgery is the change that the anterior cornea has been subjected to. This includes a reshaping of the cornea but also may involve changes in its refractive index [6]. Automated or manual keratometry is the usual way of calculating corneal power, to insert in an IOL formula. Keratometers measure the anterior cornea and not the posterior, and a "net" index of refraction is used to determine corneal power. Most keratometers assume that the radius of curvature of the posterior surface is $1.2 \mathrm{~mm}$ less than the anterior curvature [7], which in the case of refractive surgery is not true. By using a net index of refraction, the keratometers can compensate for the negative power of the posterior surface.

The alteration of the anterior corneal surface, while the posterior stays without change, leads keratometers and topographers to overestimate the corneal power. This overestimation of corneal power leads to a more hyperopic result [8] than intended after cataract surgery. In patients who have undergone hyperopic refractive surgery, the central cornea is now steeper, and that will lead to an underestimation of corneal power if using standard devices, resulting in a myopic result [9-11] after cataract surgery. 
Another source of error when calculating IOLs after refractive surgery is the incorrect estimation of effective lens position (ELP) $[5,12,13]$. The ELP is related to the anterior corneal vertex. If using a flatter (post-myopic correction) corneal power, the calculation will lead to a more forward ELP, resulting in an underestimation of the IOL power (hyperopic outcome) [14]. The opposite happens in eyes with a hyperopic laser vision correction [15].

Currently, there are many methods for choosing the correct IOL power for a patient who has undergone refractive surgery. Below we describe the methods available and attempts to calculate corneal power using historical data or objective measurements.

\section{CLINICAL HISTORY METHOD}

The clinical history method is one of the first methods ever used for the calculation of IOL power for patients who have undergone refractive surgery. It was introduced by Holladay [16], and it subtracts the change in spherical equivalent refraction induced by the refractive procedure from the known preoperative keratometric power. It is based on the theory that the final change in refractive error that the eye obtains from the refractive surgery is due only to a change (flattening) in the effective corneal power. If the change of refractive error is added to the pre-operative corneal power, it results in the present effective corneal power. If the pre- and post-operative refractive surgery data are reliable, the method can be effective. However, measurements are not always reliable. Additionally, it is difficult to determine whether the postoperative refraction is accurate and stable. Also, there is often a myopic shift in patients who have developed a cataract [17].

\section{CONTACT LENS OVER-REFRACTION METHOD}

The contact lens over-refraction method can be used when pre-operative data are unavailable. In this method, the post refractive surgery keratometric dioptres are the difference between over-refraction $(\mathrm{ORx})$ and the manifest spherical equivalent (MRx), which is then added to the base curve of the rigid contact lens $(\mathrm{BC})$ and contact lens power. $(\mathrm{P})$ : $\mathrm{K}_{\text {post }}=\mathrm{BC}+\mathrm{P}+(\mathrm{ORx}-\mathrm{MRx})[1,18]$. The biggest problem with this method is the reliability of the patient's refraction in the presence of a cataract, and with a possible decrease of best corrected visual acuity. The patient should have at least 20/80 vision in order to be subjected to this method. Moreover, it has been pointed out that this method may be unreliable [19].

\section{TOPOGRAPHIC DATA FOR CORNEAL POWER ESTIMATION}

Another method to determine the corneal power is through direct measurement, using a corneal topography and then adjusting corneal power using correction factors.

The Maloney method uses the central corneal power on the topographic map and is modified according to this formula: central power $=($ central topographic power $\times[376 / 337.5])-4.9[13]$. This formula was then modified by Wang [13], by subtracting a value greater than $4.9 \mathrm{D}$, which was originally proposed by Maloney. Shammas et al. $[20,21]$ developed a method to calculate corneal power using videokeratography with and without refractive information.

\section{DIRECT CORNEAL POWER MEASUREMINT}

Other more direct and objective ways to determine corneal power after refractive surgery have been investigated. Scanning slit topographic analysis has been investigated to measure both anterior and posterior corneal curvature. The Orbscan II (Bausch \& Lomb, USA) combines a Placido disk and slit-scanning technology. It can measure both the central zone of the cornea and the back surface. Many studies have investigated the various optical zones from which the data can be collected with the use of the Orbscan II, and it has been determined that the optimal zone is $4.5 \mathrm{~mm}$ in eyes that have undergone LASIK and $5.0 \mathrm{~mm}$ in eyes that have undergone radial keratotomy [22]. A limitation of Orbscan II elevation maps is that intracorneal opacities can obscure imaging of the posterior cornea and subsequently introduce artefacts in total corneal power calculations.

The Oculus Pentacam (Oculus, Germany) is a rotating Scheimpflug camera anterior segment imaging system that can also measure both anterior and posterior corneal curvature. Some authors suggest that the Scheimpflug camera offers improved mapping of the corneal centre by maintaining a fixed point on the vertex of the cornea [22]. The Pentacam also generates a TrueNetPower map of 
the cornea and calculates an equivalent $\mathrm{K}$ called the Holladay Report. The equivalent K (at the 4.5-mm zone) of the cornea, which has been subjected to refractive surgery, has been proposed as an accurate measure of the true corneal power [23].

\section{OPTICAL COHERENCE TOMOGRAPHY (OCT)}

OCT can be used to measure both anterior and posterior corneal power as well. It is highly valuable when preoperative data do not exist. There have been reports of good repeatability and accuracy when using OCT to measure total corneal power [24] and IOL power calculation [25, 26].

\section{CURRENT METHODS OF ACCURATELY DETERMINING IOL POWER AFTER REFRACTIVE SURGERY}

Current methods of accurately determining IOL power after refractive surgery are divided into three main categories:

- those that require preoperative data without topography;

- those that require preoperative data and topography;

- those that require no preoperative data.

\section{METHODS REQUIRING PRE-OP DATA WITHOUT TOPOGRAPHY}

The Double-K method by Aramberri, the Bypass, the Feiz-Mannis, and Masket methods all require preoperative data without the need of topography. Preoperative corneal power can be used to determine the ELP, utilising the SRK/T formula and a spreadsheet developed by Aramberri [14]. A similar calculation is performed by bypassing the corneal power change $[27,28]$. The surgeon inserts the preoperative corneal power into the chosen formula. The only calculation needed is to determine the refractive correction that occurred during the refractive surgery. Then this value is inserted as the goal refraction for emmetropia in this formula.

The Feiz-Mannis method $[4,9]$ first calculates the IOL power as if the patient has not undergone the refractive surgery. This IOL power is then adjusted by adding a correction factor to the IOL to be implanted, which is based on the LASIK-induced change in refraction. The authors have developed a nomogram that can be used if preoperative keratometry is unavailable, as long as the refractive change from the refractive surgery is available.
The Masket method [29] uses a simple IOL power corrective adjustment regression formula in which the IOL power adjustment equals 0.101 plus the spherical equivalent of the total laser treatment multiplied by -0.326 . The equation for the adjustment is: IOL power adj. $=$ LSE $\times(-0.326)+0.101(\mathrm{LSE}=$ spher ical equivalent of the total prior laser treatment).

These methods can be used with previous hyperopic refractive surgery as well.

\section{METHODS REQUIRING BOTH HISTORICAL DATA AND TOPOGRAPHY}

Methods that have been described using topographic adjustment of the corneal power and correction for effective lens position methods are either the EffRPadj (effective refractive power from the Holladay Diagnostic Summary on EyeSys device [30]) or a modified Maloney method, with insertion of the topographically measured corneal power into a double-K formula by using tables. Further iterations of this methodology have been presented using various topographers and correction factors. Eyes with previous radial keratotomy may be more difficult because of the instability of the cornea and the inaccuracy of the refractive procedure.

\section{METHODS REQUIRING NO HISTORICAL DATA OR TOPOGRAPHY}

There are methods calculating IOL power that do not require any preoperative data or topography. Shammas et al. [20] described a method to perform these calculations, which uses corrected corneal power but does not have the ELP calculation vary with the corneal curvature.

There is also the Haigis- $\mathrm{L}$ formula, which is available as IOL-Mater software and another one that can be used with data obtained from a Pentacam alone. This method is derived from corneal measurements on eyes that have or have not undergone refractive surgery.

A table (Tab. 1) with IOL power formulae or nomograms suitable for post-refractive surgery cases follows. One should note whether the formulae are designed to take standard keratometry or true corneal power.

\section{METHODS BYPASSING THE IOL CALCULATION}

There are also methods that do not use standard calculation formulas at all. The aphakic refraction 
Table 1. Intraocular lens (IOL) power formulae or nomograms suitable for post-refractive surgery cases

\begin{tabular}{|l|c|c|c|}
\hline Formula/nomogram & Input & Post-laser vision correction & Post-radial keratotomy \\
\hline Double K formula & True K & Yes & Yes \\
\hline Hoffer Q formula & True K & Yes & Yes \\
\hline Haigis-L formula & Standard K & No \\
\hline Masket formula & True K & Yes & No \\
\hline
\end{tabular}

technique determines the IOL power for emmetropia during cataract surgery. The measurements are obtained after the cataract is extracted and prior to lens implantation [31, 32].

Another way to calculate the IOL power after refractive surgery is by using any of the several available web- or app-based programs. The ASCRS Post-Refractive Calculator (www.iolcalc.org) is an efficient method for obtaining multiple IOL formulae. Several other websites are available as well. The Asia Pacific Association of Cataract and Refractive Surgeons (www.apacrs.org) provides the Barrett True-K formula for post-refractive IOL patients. Several applications are also available, using IOS or Android devices.

It is important for the surgeon to understand the advantages and limitations of the various methods of calculating IOL power after refractive surgery. Clinical studies using comparisons of the various methods would be beneficial in further understanding and developing newer, more accurate methods. It would be of true benefit if a shift toward more objective and automated data acquisition was made, in order to obtain the information that is necessary for the IOL power calculation without the risk of human error.

\section{REFERENCES}

1. Hamilton DR, Hardten DR. Cataract surgery in patients with prior refractive surgery. Curr Opin Ophthalmol. 2003; 14(1): 44-53, indexed in Pubmed: 12544810.

2. Seitz $B$, Langenbucher $A$. Intraocular lens power calculation in eyes after corneal refractive surgery. J Refract Surg. 2000; 16: 349-361.

3. Savini G, Hoffer KJ, Zanini M. IOL power calculations after LASIK and PRK. Cataract Refract Surg Today Europe 2007; April:37-44. http:// crstodayeurope.com/articles/2007-apr/0407_09-php/?single=true.

4. Feiz V, Mannis MJ. Intraocular lens power calculation after corneal refractive surgery. Curr Opin Ophthalmol. 2004; 15(4): 342-349, indexed in Pubmed: 15232475.

5. Koch DD, Wang Li. Calculating IOL power in eyes that have had refractive surgery. J Cataract Refract Surg. 2003; 29(11): 2039-2042, indexed in Pubmed: 14670401.

6. Patel S, Alió JL, Pérez-Santonja JJ. Refractive index change in bovine and human corneal stroma before and after lasik: a study of untreated and re-treated corneas implicating stromal hydration. Invest Ophthalmol Vis Sci. 2004; 45(10): 3523-3530, doi: 10.1167/iovs.04-0179, indexed in Pubmed: 15452058.

7. Holladay JT. Cataract surgery in patients with previous keratorefractive surgery (RK, PRK, and LASIK). Ophthalmol Pract. 1997; 15: 238-244.
8. Koch DD. Cataract surgery following refractive surgery. Am Acad Ophthalmol Focal Points. 2001; 19: 1-7.

9. Feiz V, Mannis MJ, Garcia-Ferrer F, et al. Intraocular lens power calculation after laser in situ keratomileusis for myopia and hyperopia: a standardized approach. Cornea. 2001; 20(8): 792-797, indexed in Pubmed: 11685053.

10. Feiz V, Moshirfar M, Mannis MJ, et al. Nomogram-based intraocular lens power adjustment after myopic photorefractive keratectomy and LASIK: a new approach. Ophthalmology. 2005; 112(8): 1381-1387, doi: 10.1016/j.ophtha.2005.03.010, indexed in Pubmed: 16061093.

11. Wang Li, Jackson DW, Koch DD. Methods of estimating corneal refractive power after hyperopic laser in situ keratomileusis. J Cataract Refract Surg. 2002; 28(6): 954-961, indexed in Pubmed: 12036636.

12. Wang Li, Booth MA, Koch DD. Comparison of intraocular lens power calculation methods in eyes that have undergone laser-assisted in-situ keratomileusis. Trans Am Ophthalmol Soc. 2004; 102: 189-96; discussion 196, indexed in Pubmed: 15747757.

13. Wang Li, Booth MA, Koch DD. Comparison of intraocular lens power calculation methods in eyes that have undergone LASIK. Ophthalmology. 2004; 111(10): 1825-1831, doi: 10.1016/j.ophtha.2004.04.022, indexed in Pubmed: 15465542.

14. Aramberri J. Intraocular lens power calculation after corneal refractive surgery: double-K method. J Cataract Refract Surg. 2003; 29(11): 2063-2068, indexed in Pubmed: 14670413.

15. Chokshi AR, Latkany RA, Speaker MG, et al. Intraocular lens calculations after hyperopic refractive surgery. Ophthalmology. 2007; 114(11): 2044-2049, doi: 10.1016/j.ophtha.2007.01.019, indexed in Pubmed: 17459483.

16. Holladay JT. IOL calculations following RK. Refract Corneal Surg. 1989; 5: 203

17. Chokshi AR, Latkany RA, Speaker MG, et al. Intraocular lens calculations after refractive surgery. J Cataract Refract Surg. 2005; 31(3): 562-570, doi: 10.1016/j.jcrs.2004.06.053, indexed in Pubmed: 15811746.

18. Argento C, Cosentino MJ, Badoza D. Intraocular lens power calculation after refractive surgery. J Cataract Refract Surg. 2003; 29(7): 1346-1351, indexed in Pubmed: 12900243.

19. Haigis W. Corneal power after refractive surgery for myopia: contact lens method. J Cataract Refract Surg. 2003; 29(7): 1397-1411, indexed in Pubmed: 12900252.

20. Shammas HJ, Shammas MC. No-history method of intraocular lens power calculation for cataract surgery after myopic laser in situ keratomileusis. J Cataract Refract Surg. 2007; 33(1): 31-36, doi: 10.1016/j.jcrs.2006.08.045, indexed in Pubmed: 17189790.

21. Shammas HJ, Shammas MC, Garabet A, et al. Correcting the corneal power measurements for intraocular lens power calculations after myopic laser in situ keratomileusis. Am J Ophthalmol. 2003; 136(3): 426-432, indexed in Pubmed: 12967794.

22. Oazi MA, Cua IY, Roberts CJ, et al. Determining corneal power using Orbscan II videokeratography for intraocular lens calculation after excimer laser surgery for myopia. J Cataract Refract Surg. 2007; 33(1): 21-30, doi: 10.1016/j.jcrs.2006.08.026, indexed in Pubmed: 17189789.

23. Holladay JT, Hill WE, Steinmueller A. Corneal power measurements using scheimpflug imaging in eyes with prior corneal refractive surgery. J Refract Surg. 2009; 25(10): 862-868, doi: 10.3928/1081597X20090917-07, indexed in Pubmed: 19835326.

24. Tang M, Li Y, Avila M, et al. Measuring total corneal power before and after laser in situ keratomileusis with high-speed optical coherence 
tomography. J Cataract Refract Surg. 2006; 32(11): 1843-1850, doi: 10.1016/j.jcrs.2006.04.046, indexed in Pubmed: 17081867.

25. Tang M, Li Y, Huang D. An intraocular lens power calculation formula based on optical coherence tomography: a pilot study. J Refract Surg. 2010; 26(6): 430-437, doi: 10.3928/1081597X-20090710-02, indexed in Pubmed: 20677729.

26. Tang M. Intraocular lens power calculation based on fourier-domain optical coherence tomography. Invest. Ophthalmol. Vis. Sci. 2010; 51: p. E-Abstract 5692.

27. Ladas JG, Stark WJ. Calculating IOL power after refractive surgery. J Cataract Refract Surg. 2004; 30(12): 2458; author reply 2458-9, doi: 10.1016/j.jcrs.2004.10.013, indexed in Pubmed: 15617892.

28. Walter KA, Gagnon MR, Hoopes PC, et al. Accurate intraocular lens power calculation after myopic laser in situ keratomileusis, bypassing corneal power. J Cataract Refract Surg. 2006; 32(3): 425-429, doi: 10.1016/j.jcrs.2005.12.140, indexed in Pubmed: 16631050.

29. Masket S, Masket SE. Simple regression formula for intraocular lens power adjustment in eyes requiring cataract surgery after excimer laser photoablation. J Cataract Refract Surg. 2006; 32(3): 430-434, doi: 10.1016/j.jcrs.2005.12.106, indexed in Pubmed: 16631051.

30. Holladay JT. Corneal topography using the Holladay Diagnostic Summary. J Cataract Refract Surg. 1997; 23(2): 209-221, indexed in Pubmed: 9113572.

31. Ianchulev T, Salz J, Hoffer K, et al. Intraoperative optical refractive biometry for intraocular lens power estimation without axial length and keratometry measurements. J Cataract Refract Surg. 2005; 31(8): 1530-1536, doi: 10.1016/j.jcrs.2005.01.035, indexed in Pubmed: 16129287.

32. Mackool RJ, Ko W, Mackool R. Intraocular lens power calculation after laser in situ keratomileusis: Aphakic refraction technique. J Cataract Refract Surg. 2006; 32(3): 435-437, doi: 10.1016/j.jcrs.2005.11.045, indexed in Pubmed: 16631052.

33. Hodge C, McAlinden C, Lawless $M$, et al. Intraocular lens power calculation following laser refractive surgery. Eye Vis (Lond). 2015; 2: 7, doi: 10.1186/s40662-015-0017-3, indexed in Pubmed: 26605363. 